\title{
Courtship and Mating Behavior of the Cockroach Oxyhaloa deusta [Thunberg, 1784] (Blaberidae, Oxyhaloinae): Attraction Bioassays and Morphology of the Pheromone Sources
}

\author{
Marie-Hélène Lizée ${ }^{1} \cdot$ Bernard Barascud $^{1} \cdot$ Jean-Pierre Cornec $^{1} \cdot$ Leam Sreng $^{1}$
}

1 Institut Méditerranéen de Biodiversité et d'Écologie marine et continentale (IMBE), Aix Marseille Université, CNRS, IRD, Avignon Université, IMBE UMR 7263, Site St Charles - Case36 - 3, place Victor Hugo, 13331, cedex 03 Marseille, France

\begin{abstract}
In this paper, we focus on the reproductive behavior of the cockroach Oxyhaloa deusta. Within the Oxyhaloinae subfamily, mating strategies and glandular areas involved in pheromone production have been studied for several genera belonging to the Nauphoetini and Gromphadorhini tribes. However, this is the first time that courtship and mating behavior have been explored within the genus Oxyhaloa, and in a more general way within the Oxyhaloini tribe. This work, comprising behavioral observations, olfactometric bio-assays and morphological data, highlights unusual behaviors and novelties in potential sex pheromone gland location, in both males (tergite 8) and females (supra-valvular area). Surprisingly, our results also indicate that mate finding is initiated by the female. This is quite remarkable inasmuch as the Oxyhaloinae subfamily is the only cockroach group in which males initiate mate finding by means of a sex pheromone, emitted during the calling posture by extending abdominal tergites. In the Oxyhaloinae subfamily, this occurrence of various reproductive behavioral patterns (including all the mating patterns known at present in Blattaria) in closely-related species is striking, and makes this group a suitable model for studying the changes in mating behavior correlated with the location of sexual glands.
\end{abstract}

Keywords Oxyhaloinae $\cdot$ Blaberidae $\cdot$ sex pheromones $\cdot$ mating patterns $\cdot$ exocrine glands $\cdot$ chemical communication 


\section{Introduction}

In cockroaches, courtship and mating behaviors are characterized by intense chemical communication that relies on the emission of sexual pheromones. Two types of chemical signals, which intervene successively in sexual behavior, can be distinguished: long-range and short-range signals. First, a long-range volatile attractant is emitted by one of the sexual partners (male or female) to elicit orientation of a potential mate. This pheromone emission, aimed at attracting the other sex, is accompanied by characteristic postures defined as calling postures or behaviors (Bell et al. 2007; Gemeno and Schal 2004). Once the sexual partners contact, short-range chemical signals are then involved. This second type of signals comprises (i) contact or close-range pheromones that are perceived by means of antennal contact, and/ or (ii) tergal secretion by the male of "aphrodisiacs" containing both proteinaceous and volatile compounds (Brossut et al. 1975; Sreng 1979a). This tergal glandular secretion (Roth 1969; Brossut and Roth 1977) is licked by the female (i.e. perceived with the mouth parts) while she mounts the male's back, and helps to maintain both partners in the right position to engage the genitalia.

In cockroaches, depending on the species, it is either the male or the female that initiates mate finding by emitting the long-range sexual attractant. Here, several specific characteristics, such as the type of locomotion, sexual dimorphism, the degree of gregariousness or even the foraging habits, seem to be involved (Gemeno and Schal 2004). Since the work of McKittrick (1964), who produced the most widely accepted cockroach taxonomy, it is accepted that three main families contain most cockroach species (4208 species out of 4641 - Beccaloni and Eggleton 2013): Blattidae [Blattoidea], Ectobiidae and Blaberidae [Blaberoidea]. These three families differ in terms of morphology, physiology and behavior, but this division also appears in chemical communication (Tokro 1984). Thus, in Blattidae and in Ectobiidae, typically the female attracts males by releasing long-range pheromones from atrial or pygidial glands during the calling posture (Blomquist et al. 2004). However, in Blaberidae the pattern is less clear. In some genera, such as Blaberus, Byrsotria [Blaberinae] or Pycnoscelus [Pycnoscelinae], it is the female that initiates mate finding (Tokro 1984), while in the Oxyhaloinae subfamily [Blaberidae], it is the males that release the longrange sex attractant (Sreng 1993).

Unlike the other cockroach groups, males of the Oxyhaloinae [Blaberidae] produce both the aphrodisiac (from tergal glands) and the sex attractant (from sternal glands) (Sreng 1984). They adopt characteristic postures to release the long-range sex attractant, by extending their abdomens upward to expose sternal glands that are hidden between sternites in normal position (Sreng 1979b, 1984, 1993). After this first step, which seems to be general for the Oxyhaloinae subfamily, patterns of behavioral sequences during mating differ among species. Thus, three types of behavioral patterns (A, B and C) can be distinguished in Oxyhaloinae species.

In Nauphoeta cinerea [Olivier, 1789] and Leucophea (Rhyparobia) maderae [Fabricius, 1781] (Sreng 1993; Roth and Barth 1967), after the meeting of the sexual partners, antennal contact with the female stimulates the male to raise his wings, revealing the tergal glands that produce the aphrodisiac. While the female mounts his abdomen to feed or nibble on this tergal secretion, the male attempts 
copulation. This mating sequence, characterized by male wing-raising and female feeding behavior, corresponds to type A pattern (Sreng 1993), and is observed in most cockroach species (e.g. Periplaneta Americana [Linnaeus, 1758], Blattella germanica [Linnaeus, 1767]) (Roth and Willis 1952, 1954; Barth 1968; Gemeno and Schal 2004). There are two other behavioral patterns in which the female does not feed on the male's tergal secretion. In the type B pattern (represented by Jagrehnia madecassa [Saussure, 1891] (Sreng 1993), and known in Pycnoscelus indicus [Fabricius, 1775] (Roth 1970)), the male, without raising his wings, mounts the female's back and curves his abdomen under the female's to copulate. Finally, in type C pattern (represented by the wingless genus Gromphadorhina), the male does not mount his partner, but moves back toward the motionless female to copulate end-to-end (Sreng 1993). It has been suggested that the location of the pheromone glands and the type of mating behavior are closely related (Roth 1969; Sreng 1993, 2006). Indeed, both the production of the signal from the sender and its perception from the receiver, as well as the associated response, need to coevolve, as the stability of the interaction depends on these two processes (Maynard-Smith and Harper 2003).

In the Oxyhaloinae subfamily, the occurrence of the three reproductive behavioral patterns in very close species is striking, and makes this group a suitable model for studying the changes in mating behavior correlated with the location of sexual glands. The present study focuses on the Oxyhaloinae species, Oxyhaloa deusta [Thunberg, 1784], that is naturally distributed in southern Africa (Beccaloni 2007). Little is known about $O$. deusta, which is typically reared to feed domestic reptiles because of its small size (males $\approx 12 \mathrm{~mm}$; females $\approx 18 \mathrm{~mm}$ ). Both sexes are winged and naturally occur under stones in a variety of vegetation types, mostly in subtropical areas (Picker et al. 2002). The available information about its behavior and ecology suggests that males may produce a long-distance sex pheromone to attract females (Picker et al. 2002). This would be congruent with the behavior of the other seven Oxyhaloinae species that have been studied (Sreng 1993). However, to date, no behavioral observations or tests have been performed to support this affirmation for $O$. deusta, and in a more general way for the Oxyhaloini tribe (Roth 1971).

Princis (1961) and Roth (1971) separate the Oxyhaloini tribe in a class of its own due to the particular morphology of the male genitalia. As genitalia and copulation evolve together with the communication system (Alexander and Otte 1967; Eberhard 1985, 1991, 2010; Rowe and Arnqvist 2011), this morphological particularity makes us hypothesize that the Oxyhaloini tribe should have a special place within the Oxyhaloinae subfamily in terms of sexual behavior and location of the sexual glands. In fact, complex co-evolutionary dynamics between males and females can shape genital structures (Ah-King et al. 2014).

The purpose of this study is to analyse the sexual behavior of $O$. deusta, i.e. courtship and mating, and to determine the glandular origin of the chemical signals intervening in the different behavioral sequences. The results, comprising (i) behavioral observations, (ii) olfactometric tests, and (iii) morpho-anatomical data, are discussed from an evolutionary point of view in comparison with those obtained from other Oxyhaloinae species (Sreng 1979b, 1984, 1993) and, in a more general way, from other cockroach species. 


\section{Material and Methods}

\section{Insects}

The colony of $O$. deusta was reared in a plastic aquarium $(30 \times 25 \times 20 \mathrm{~cm})$ maintained at a constant temperature of $26^{\circ} \mathrm{C}( \pm 2)$ and $70 \%$ relative humidity under a reversed $12: 12 \mathrm{~h}$ dark:light regime. Apples, dry cat food and water were provided ad libitum. Adults of both sexes, used for behavioral observations and Y-olfactometer assays, were randomly isolated from the stock colony at last nymphal instars before adult ecdysis. To avoid any mechanical or olfactory stimuli between the sexes, males and females were isolated in cylindrical plastic boxes $(7 \mathrm{~cm}$ in height $\times 3 \mathrm{~cm}$ in diameter) containing food and water.

\section{Behavioral Observations}

All observations were carried out during the first $3 \mathrm{~h}$ of the dark period (according to preliminary observations, these first $3 \mathrm{~h}$ of the dark period corresponds to peak activity), in a darkroom lit by a photographic red lamp. Observations were performed in a glass aquarium $(18 \times 30 \times 20 \mathrm{~cm})$ containing several pairs of virgin insects (between 3 to 5 male-female couples). Only the characteristic sequences were reported, following the main events of the mating behavior in cockroaches: (i) mate finding, (ii) contact, (iii) male release of tergal aphrodisiacs (if occurring), and then (iv) attempt at copulation. Virgin females ( 1 to 7 days old) and males (7-15 days old) were used.

The behavioral sequences were recorded using a digital Panasonic camera (Lumix FZ150) in order to be able to re-examine the sequences in more detail afterwards.

\section{Attraction Tests}

The Y-maze olfactometer consisted in a glass tube $(2 \mathrm{~cm}$ in diameter) with a $30 \mathrm{~cm}$ long common-arm, dividing into two $20 \mathrm{~cm}$-long choice arms (the angle between the two choice arms was $80^{\circ}$ ) (Sreng 1990). Each individual was placed in an adaptation box $(6 \times 9 \times 5 \mathrm{~cm})$ at least 2 min before each test. This adaptation box comprised a screen door that could be raised to allow entry into the common arm at the starting point " $\mathrm{O}$ ". Hence, each individual was allowed to move into the common-arm, turning either right or left to reach the arrival points " $\mathrm{A}$ " or " $\mathrm{B}$ ".

In order to test the response of males to female odors 3 types of experiments were performed. First, a control test was performed with ambient-air flux $(1200 \mathrm{ml} / \mathrm{min})$ emanating from the arrival points " $\mathrm{A}$ " and "B" (air-pump EHEIM 400, GmbH \& Co $\mathrm{KG}$, Germany). This control test was designed to assess trends for a potential turning phenomenon and to compensate this phenomenon if it occurred (Sreng 1990).

Then, a test was performed with ambient-air flux emanating from point "A" (as in control test), while the air flux emanating from point " $\mathrm{B}$ " was passing through a plastic box (i.e. stimulus-box) containing 4 virgin females (0-6 days old). As we did not know the condition of pheromone release, we used these virgin females as a "stimulus association". Finally, another test was performed under the same conditions as previously, except that 1 virgin female was forced to open her genitalia. This female was wrapped in a piece of sponge to minimize wounds and then slightly squeezed with a paper clip. 
The control test was performed on 21 males of O.deusta and the two other tests were each performed on 42 males of O.deusta (5-10 days old). Each individual test was run for a maximum of $5 \mathrm{~min}$ from the starting point "O". If a male chose one of the olfactometer arms in less than $5 \mathrm{~min}$, he was considered to have made a choice. After every 5 responding individuals, the olfactometer was cleaned with $90 \%$ ethanol to prevent contamination by pheromones or chemicals.

Following the same procedure, we performed 3 additional experiments to test the response of females to male odors (using 20 virgin females $0-5$ days old): a control test, a test with 3 males in the stimulus-box and a test with a squeezed male (forcing him to extend tergite 8 ).

Each responding individual was used only once in the various experiments. Moreover, the set of individuals used as stimulus (4 virgin females in the first experiment, 2 virgin males in the second experiment) was refreshed with a new set of individuals after 5 runs of responding individuals. After these attraction tests, all insects were freed.

$\chi^{2}$ tests were used to evaluate whether the results differed from a 50/50 distribution between the two olfactometer arms $(* P<0.05, * * P<0.01$, $* * * P<0.001$, n.s.: $P>0.05)$.

\section{Localization and Morphology of Glands Producing Sexual Pheromones}

All the individuals dissected for this study were previously anaesthetized with carbon dioxide and then were instantly decapitated with fine scissors.

\section{Light Microscopy}

The male and female abdominal tergites and sternites were dissected longitudinally along pleural membranes, freed of underlying tissues, and treated in a $10 \% \mathrm{NaOH}$ solution. For the female genital area, external genitalia were exposed by cutting the pleural membrane of segment VII and pulling down sternite VII and treated in $\mathrm{NaOH}$ solution as above. After several rinses in water and dehydration in alcohol, the specimens were slide-mounted in Canada balsam medium to be examined under a light microscope (Nikon-SMZ80) coupled with a camera (Nikon digital sight DS-Fi1). The glandular zones were determined according to the density of glandular orifices in the area of each tergite, sternite or genital area.

\section{Scanning Electron Microscopy}

The body parts bearing glands were dissected for both male and female $O$. deusta. The samples were rinsed with a detergent (Briochin ${ }^{\circledR}$ ) in order to rid them of an eventual fatty coating and then dehydrated in alcohol. For internal surface observation, the male's tergite 8 was treated with $10 \% \mathrm{NaOH}$ for $1 \mathrm{~h}$ to remove underlying tissues, rinsed several times with distilled water and dehydrated in alcohol. A layer of gold was deposited by sublimation. Following this gold-coating, tissues were examined using scanning electron microscope (Philips XL 30 ESEM). 


\section{Histology}

The techniques used were those described in Gabe (1968). Adult abdominal tergites and sternites bearing glands of males and females were fixed in Bouin's liquid fixation. After dehydration and paraffin embedding, the abdominal preparations were sectioned at $7 \mu \mathrm{m}$ and stained with hematoxylin and eosin.

\section{Results}

\section{Mating Behavior}

\section{Female Calling Behavior}

In the box where $O$. deusta was reared, males were observed courting newly emerged adult females, or even older females during parturition. In fact, in both of these processes, the female assumed a particular posture in which the terminal abdominal segments were partially open, indicating that something instantaneously excited males when a female exposed her genital region.

This hypothesis was supported by behavioral observations under controlled conditions. First, when virgin females were placed in the aquarium with virgin males, the young males became instantly sexually excited (in less than $1 \mathrm{~s}$ ). This revealed that some volatile compounds could elicit a response of the males, even before the partners physically contacted. Moreover, three females were also observed adopting a characteristic calling posture probably associated to the process of releasing pheromones (Fig. 1). A female in this calling posture extended her hind legs, and alternated between two positions in less than $1 \mathrm{~s}$ : (i) the abdomen was raised and extended above the ground (Fig. 1a), then (ii) the abdomen was lowered and compressed while she slightly raised her wings (Fig. 1b). This sequence of movements can be carried out once or repeated several times.

\section{Courtship and Copulation}

A sexually excited male immediately started courting by running closely behind the female (Fig. 2a) while he was periodically curving his abdomen towards her head (Fig. 2b), and more specifically in the direction of her antennae. This particular
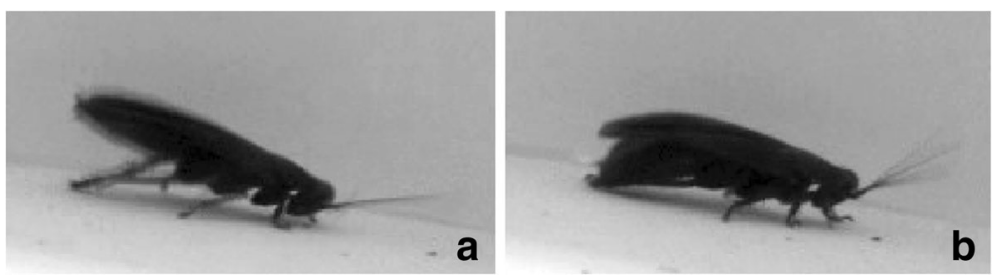

Fig. 1 A female Oxyhaloa deusta performing the potential calling posture: (a) she raises and extends her abdomen above the ground and then (b) she lowers and compresses her abdomen while the wings are slightly raised 


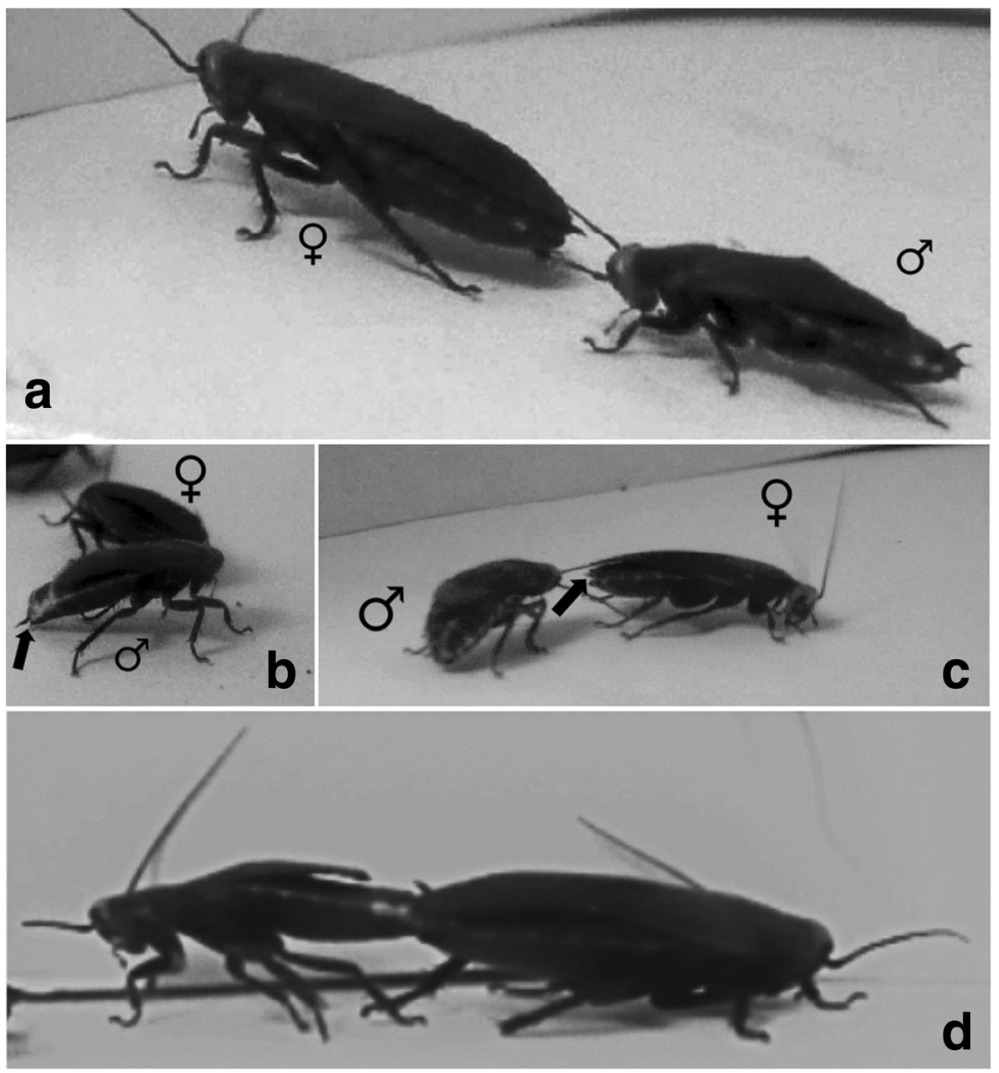

Fig. 2 Courtship sequence in Oxyhaloa deusta: (a) the male follows the female with his antennae placed on each side of her abdomen, then, (b) while he is still following the female, he curves his abdomen from one side to the other, exposing his 8th tergite (arrow) towards the female's antennae. (c) A receptive female exposing her supra-valvular gland (arrow) while the courting male is following her. (d) A male (on the left) and a female (on the right) remaining end-to-end in opposed position until the copulation is terminated

movement of curving the abdomen from left to right, while he was following the female, exposed the anterior part of the male's tergite 8 (cf. arrow in Fig. 2b).

If the female was not receptive, she repelled the suitor by kicking him with her hind legs. In this case, the male could abort courtship, or persist by running behind the female with his antennae placed on each side of her abdomen (as in Fig. 2a). This part of the courtship may last a long time until the female showed signs of sexual receptivity. Usually the male repeated the entire display several times, before the female accepted the copulation.

If the female was receptive, she paused, with the male staying just behind her, and opened intermittently her terminal abdominal segments exposing her genitalia (cf. arrow in Fig. 2c). This could incite the male to continue courtship and to attempt copulation. Then, the male extended once again the tip of his abdomen towards the female's antennae (the two partners temporarily being side by side in opposite directions), and, in the same movement, he bent his abdomen beneath that of the female attempting to grasp her genitalia. Finally, both the male and female remained end-toend for 10 to $15 \mathrm{~min}$ during the copulation (Fig. 2d). Another series of photographs 
(involving an immobile teneral female and thus easier to record in video) is available in supplementary material and shows in more details the last step in which the male grasps the female's genitilia (ESM1).

However, it should be emphasized that these behavioral sequences were recorded in experimental conditions. The longest recorded copulation lasted for $18 \mathrm{~min}$, but all the others were shorter in duration. In the aquarium, the mating partners were generally disturbed by other individuals and seemed to stop the copulation before it was normally terminated. The copulation may take longer in natural conditions.

\section{Bioassays (Fig. 3)}

\section{Response of Males to Female Odors}

Ninety percent (19/21) of the $O$. deusta males tested in the olfactometer to perform the control test responded. Of these 19 individuals that responded, 10 males chose one of the Y-arms, while 9 males chose the other. This proportion was not significantly different from the expected 50/50 distribution between the two olfactometer arms $\left(\chi^{2}{ }_{1}=0.04 ; p=0.83\right)$ highlighting the absence of any trend to turn either to the right or to the left (Fig. 3a).

Ninety-three percent (39/42) of the males used for the first test responded. Of these 39 individuals, 22 males chose the Y-arm containing females, while 17 males chose the empty arm. This ratio (17/22) was not significantly different from a 50/50 distribution between the two olfactometer arms $\left(\chi^{2}{ }_{1}=0.46 ; p=0.57\right)$, (Fig. 3b).
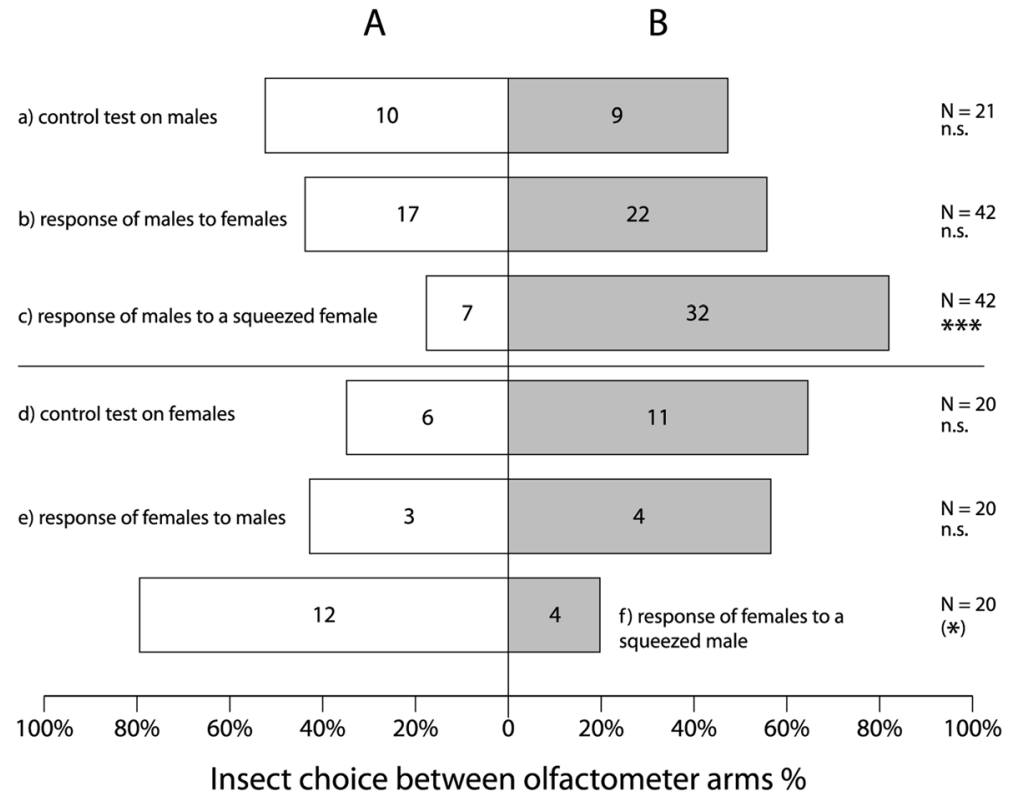

Fig. 3 Results of the different experiments showing the choice of Oxyhaloa deusta between the olfactometer arms in percentage, and statistical significance of the difference from a 50/50 distribution (* $p<0.05$; ** $p<0.01$; *** $p<0.001$; n.s. $p>0.05 ;(*)$ nearly significant - here $p=0.06)$. Except for the control tests (a and d), the "stimulus box" corresponds to arm B 
Another test was performed in order to assess the attractiveness of females, forcing them to open their terminal abdominal segments. Ninety-three percent (39/42) of the males used for this second test responded. Of these 39 individuals, 32 males chose the Y-arm containing females, while 7 males chose the empty arm. This ratio (7/32) was significantly different from the $50 / 50$ ratio $\left(\chi^{2}{ }_{1}=11.92 ; p=0.0008\right)$ (Fig. $\left.3 c\right)$, and showed that squeezed females were attractive to males.

\section{Response of Females to Male Odors}

Eighty-seven percent $(17 / 20)$ of the $O$. deusta females tested in the olfactometer to perform the control test responded. Of the 17 individuals that responded, 6 females chose one of the Y-arms, while 11 females chose the other. This proportion was not significantly different from the expected 50/50 distribution between the two olfactometer arms $\left(\chi_{1}^{2}=1.26 ; p=0.26\right)$, highlighting the absence of any trend to turn either to the right or to the left (Fig. 3d).

One test was performed in order to assess the attractiveness of males. Only $35 \%$ $(7 / 20)$ of the females used for this test responded. Four of these 7 females chose the Yarm containing the males while 3 females chose the empty arm. This ratio (3/4) was not significantly different from the $50 / 50$ ratio $\left(\chi_{1}^{2}=0.13 ; p=0.72\right)$ (Fig. $3 \mathrm{e}$ ).

Finally, one more test was performed to assess the attractiveness of a male, forcing him to expose tergite 8 . Of the 16 females that responded (80\%), 12 females chose the empty arm, whereas 4 females chose the Y-arm containing the squeezed male. The Chi2 test revealed that this ratio (12/4) was nearly significantly different from the 50/50 ratio $\left(\chi^{2}{ }_{1}=3.46 ; p=0.06\right)$, highlighting that the majority of females tested here chose the empty arm (Fig. 3f) and were not attracted by the squeezed male (which tended to repel them).

\section{Localization and Morphology of Glands Producing Sexual Pheromones}

\section{Glands Producing Sexual Pheromones in Males of O. deusta}

During courtship, the male clearly exposes to the female antennae a tergal distal abdominal region (Fig. 2b). Under light microscope, the observation of in toto preparations of males' sternites and tergites reveals a glandular area on the 8th tergite only. No other differentiated glandular area was found elsewhere on males' bodies. The anterior part of $\mathrm{T} 8$ exhibits numerous depressions that are overlapped by $\mathrm{T} 7 \mathrm{in}$ normal position (Fig. 4a-c). On an average-sized male (approximately $1.2 \mathrm{~cm}$ ), the region bearing depressions approximates $1.50 \mathrm{~mm}^{2}$ in area (white dashed area on Fig. 4b). These depressions vary in size (from $1 \mu \mathrm{m}$ to $25 \mu \mathrm{m}$ ) (Fig. 4d-e), gathering a varying number of assumed glandular orifices according to depression size (about 1-7 orifices / depression) (Fig. 4f). This results in differences in density of glandular orifices on T8 (Fig. $4 \mathrm{e}-\mathrm{f}$ ).

On the internal face of the cuticle, these depressions correspond to sclerotinized dome-like structures from which cuticular canals are emerging (Fig. 4g). These canals are surrounded by the cuticle as revealed in the longitudinal section through tergites 7 and 8 where they are stained with the same characteristic colour as the cuticle (arrows on Fig. 4h). They could constitute collecting canals which bring 


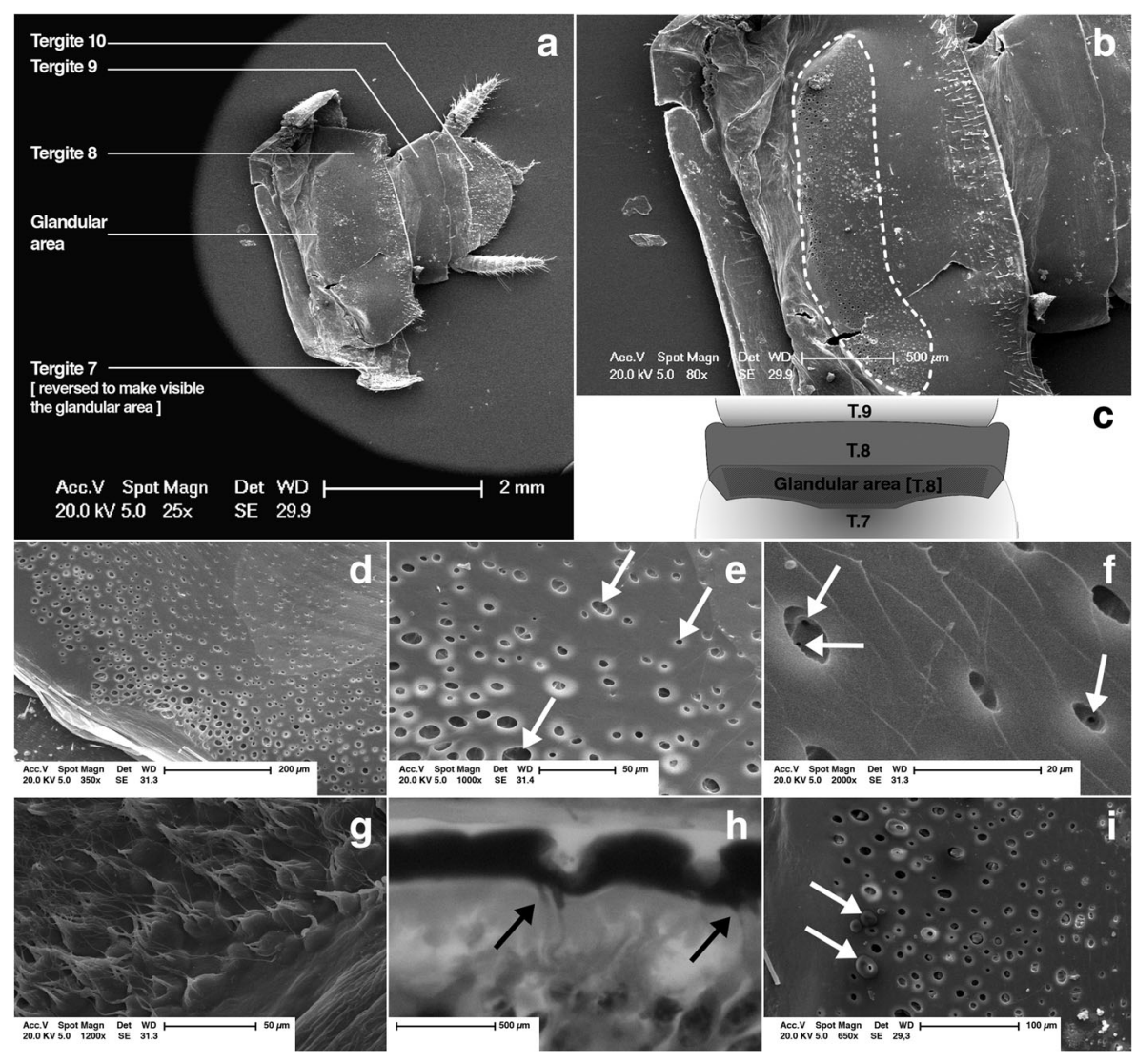

Fig. 4 Localization and morphology of the potential pheromone source in male Oxyhaloa deusta. Scanningelectron microscope (SEM) images showing localization of the glandular area on the anterior part of the 8th tergite (a, b) as illustrated on the schematic drawing (c) (on $\mathbf{b}$ the glandular area is highlighted by a white dashed line). SEM images showing the external morphology of the glandular depressions with various magnification factors $(\times 350-4 \mathrm{~d}, \times 1000-4 \mathrm{e}$ and $\times 2000-4 \mathrm{f})$, and the corresponding structures on the internal face of the cuticle revealing ducts emerging from dome-like structures $(\times 1200-4 \mathrm{~g})$. On $4 \mathrm{e}$, the arrows indicate three depressions of varying size (corresponding to dome-like structures on the internal face $-4 \mathrm{~g}$ ) into which a varying number of glandular orifices open (three of these orifices are indicated by white arrows on 4f), corresponding to ducts on the internal face $-4 \mathrm{~g}$. These ducts, of cuticular nature, as visible on the histological preparation (black arrows) (light microscope image $\times 600-4 \mathrm{~h}$ longitudinal section), are parts of class-3 glandular units which bring the secretory material outside the insect body (SEM image $\times 650-4 \mathrm{i}$, showing external side of the cuticle with black arrows highlighting secretions)

the secretory material outside the insect body, as can be seen on some preparations where the removal of the fatty coating failed (arrows on Fig. 4i). These cuticular ducts reveal the presence of class-3 glandular cells, i.e. units composed of one secretory cell and one canal cell.

\section{Glands Producing Sexual Pheromones in Females of O. deusta}

The courting behavior of the male, running behind the receptive female which exhibits her genital region, indicates that this area in the female abdomen might release chemical signals attracting or exciting the male. 
As it was done previously for males, slides with in-toto preparations from females were examined under a light microscope, looking for glandular orifices. But no evidence of any differentiated glandular region was found on abdominal tergites and sternites of females, even on T10, and no pygidial gland was found.

However, a particular region of approximately $0.80 \mathrm{~mm}^{2}$ (once unfolded), located between the anus and the three pairs of ovipositor valves (Fig. 5a-c), exhibits numerous orifices (Fig. 5d). These assumed glandular orifices are slightly sclerotinized and organized in rosettes which comprise a number of orifices ranging from one to about thirty (Fig. 5e-f). These rosettes are regularly distributed over the potential glandular zone, resulting in a density of approximately 10,000 orifices for $1 \mathrm{~mm}^{2}$.

Finally, it is worth noting that under optical microscopy, particular "noodle-like" structures seem to emerge (white arrows on Fig. $5 \mathrm{~g}$ ) from the numerous orifices (black arrows on Fig. $5 \mathrm{~g}$ ). These canals are sclerotinized, as revealed by their characteristic tint on the histological preparation (white arrows on Fig. 5h), and highlight the occurrence of class-3 glandular units.

To refer to this assumed glandular region, never hitherto named (see Snodgrass 1935), we chose the term "supra-valvular gland".

\section{Discussion}

\section{Initiation of Mate Finding by the Female and Mating Behavior Pattern of a New Type}

The Oxyhaloinae subfamily is known as the only cockroach group in which males are the releasers of both the long-range sex attractant (sex pheromone) and the aphrodisiac (Sreng 1984). In the Oxyhaloinae subfamily, the first identified male sex pheromone was called "Seducin" by Roth and Dateo (1966) and was isolated from sternal glands of $N$. cinerea (Sreng 1990). This type of male sex pheromone, attracting females from a distance, has also been found in seven other Oxyhaloinae species (Sreng 1993). However, on the basis of our behavioral observations, two hypotheses can be formulated:

(i) unlike the other Oxyhaloinae species (Sreng 1993), and in contrast to Picker et al.'s (2002) assumption on the male producing a long-range attractant, mate finding seems to be initiated by the female in the species $O$. deusta;

and (ii) the female could attract males in a voluntary way (calling posture) or not (during parturition or moulting).

This attraction of a potential mate by the female is supported by the attraction tests with the Y-maze olfactometer, and is reinforced by the occurrence of a characteristic calling posture in the female $O$. deusta, potentially associated with pheromone release. Firstly, the orientation of a significant majority of males toward the box containing the squeezed females reveals that mate finding could be mediated by certain chemical compounds emitted by the females, while the presence of males in the stimulus-box does not elicit any particular response from the females (which tend not to move), or even repels them (when the male is squeezed). Secondly, this female sex pheromone seems to be emitted under particular conditions (i.e. when her supra-valvular area is exposed), as revealed by the absence of significant choice difference between 

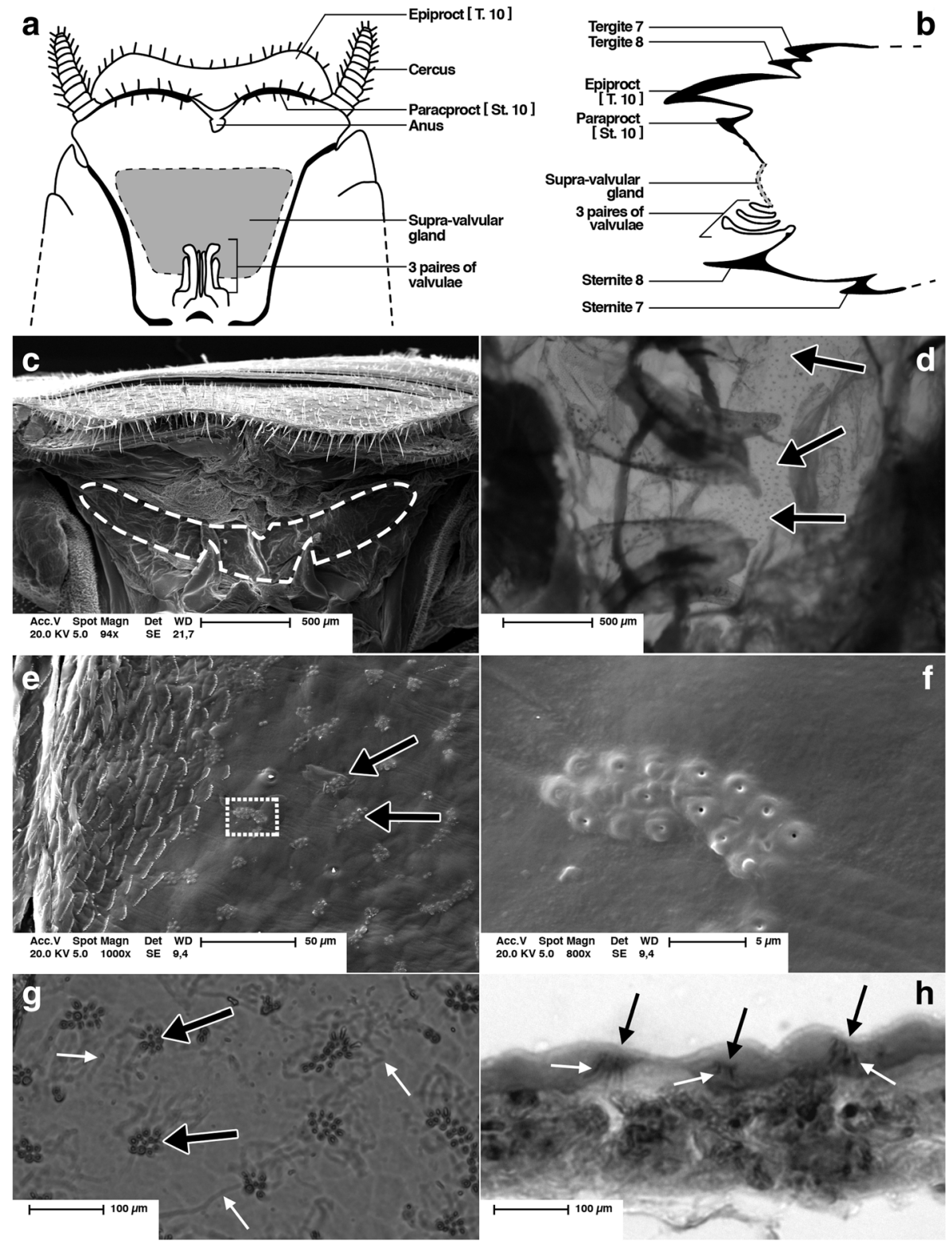

Fig. 5 Localization and morphology of the potential pheromone source in female Oxyhaloa deusta. Schematic drawings showing the localization of supra-valvular area bearing the potential pheromone glands $(5 \mathrm{a}$ ventral view, $5 \mathrm{~b}$ lateral view). Photographs showing the glandular area (white dashed line), located posteriorly between the 3 pairs of valvulae and the anus (SEM image $\times 94-5 \mathrm{c}$, and light microscope image $\times 100-5 \mathrm{~d}$ ). On $5 \mathrm{~d}$, the orifices organized in rosettes are visible as slight punctuations (black arrows). SEM images showing the external morphology of the glandular orifices (black arrows) with various magnification factors $(\times 1000-5 \mathrm{e}$ and $\times 8000-5 \mathrm{f}$ ). The microphotograph $5 \mathrm{f}$ corresponds to the area highlighted by the white dashed rectangle on 5e. Light microscope images showing the glandular orifices (black arrows) on in-toto preparation $(\times 600-5 \mathrm{~g})$ and the corresponding cuticular ducts (white arrows) on histological preparation $(\times 600-5 \mathrm{~h}$ transversal section) 
olfactometer arms when females are not squeezed, while the attractive squeezed female is forced to adopt a posture similar to the calling posture during which the supravalvular area is exposed. So $O$. deusta could be the first species in the Oxyhaloinae subfamily in which the female is observed emitting the long-range sexual attractant to which males respond from a distance.

As mentioned above, the exposure of this glandular area can occur in a voluntary way or not. Males of $O$. deusta were observed courting teneral females just after emergence (see ESM1.). This postemergence attractiveness of females seems common in Blaberidae species and has been previously observed in Diploptera punctata [Eschscholtz, 1822] (Roth and Willis 1955; Stay and Roth 1958), J. madecassa (Sreng 1993) and Schultesia nitor [Grandcolas, 1991] (Monceau and van Baaren 2012). In their study, Monceau and van Baaren (2012) allude to the female-like sexappeal characteristic of exuvia products (but see also Roth and Willis 1952; Schal and Bell 1983). Males of $O$. deusta were also observed courting older females just after parturition. In both of these processes (moulting and parturition), the female tends to involuntarily expose her supra-valvular area where specialized glands have been found (see below, part 4.2).

Moreover, this is the first time that females of the Oxyhaloinae subfamily have been observed adopting a calling posture in the process of releasing pheromones. This behavior might have been unnoticed to date because it is less visible than in other cockroach groups, such as P. americana (Roth and Willis 1952; Barth 1970), B. germanica (Liang and Schal 1993) or Parcoblatta lata [Brunner, 1865] (Gemeno et al. 2003). But, once recognized, the calling behavior of females of $O$. deusta is quite similar to the characteristic calling behavior reported in other cockroach families (e.g. Willis 1970; Hales and Breed 1983; Schal and Bell 1985; Liang and Schal 1993; Gemeno et al. 2003). Typically, a calling female extends her hind legs, lifting her abdomen above the ground, and then exposes her genital area. This calling behavior of the female may also have been unnoticed because the male is much more active, and in a more visible way, than the female during courtship. Besides, it is now recognized that studies on mating behaviors and genitalia suffer of strong male bias in a general way (Ah-King et al. 2014).

Hence, the courtship behavior in $O$. deusta does not involve either male wingraising, or female mounting to feed on male aphrodisiacs as in type A pattern (Sreng 1993). Males do not mount the females either, as in type B pattern. But, even if partners copulate end-to-end as in type $\mathrm{C}$ pattern, the way the male twists the tip of his abdomen while following the female recalls in parts the mating behavior of $J$. madecassa or P. indicus of type B pattern (Roth and Willis 1958; Roth 1970; Sreng 1993). So, mating behavior in O. deusta seems to represent a new and alternative pattern (neither type A, B, nor C), that does not correspond to Sreng's classification.

The exposure of the male's 8th tergite could serve as an excitatory stimulus acting by olfactory processes (as type $\mathrm{C}$ pattern) and seems to be the major key in deviations from Sreng's classification of mating behaviors (Sreng 1993). This short range "mutual exchange" or "mutual appreciation" of volatile chemical messages between the male and the female, potentially mediated by the tergal gland and the supra-valvular gland respectively, recalls the female mounting and feeding behavior of type A behavior pattern (e.g. in B. germanica or R. maderae 
where tergal secretions are considered as a nuptial gift - Nojima et al. 1999a; Nojima et al. 1999b; Mondet et al. 2008), or the male mounting of type B pattern (e.g. J. madecassa - Sreng 1993).

So, the change from behavioral patterns of types A and B on one hand, to this new behavioral pattern observed in $O$. deusta and type $\mathrm{C}$ pattern on the other hand, seems to correspond to a shift in chemical communication from contact compounds to more volatile compounds.

In our olfactometric tests, the absence of response of females to male odors is however confusing and worth being discussed. We have no explication for this lack of response, or for the apparent repelling effect of the squeezed male. We could hypothesize the emission of a warning signal by the squeezed male which may explain an inhibition of female responses.

\section{Class-3 Glandular Cells with Unprecedented Locations both in Males and Females}

As mentioned above, there is a close relationship between the emission of pheromonal signals from specific glands and the associated behavior, so that courtship and mating behaviors are precious clues to localize the glands producing these pheromones (Sreng 2006). When the mating behavior corresponds to type A pattern, specialized macroscopic structures, such as tufts of setae, cuticular ridges and fossae, are found on males' abdominal tergites (e.g. B. germanica, Supella longipalpa [Fabricius, 1798] - Roth 1969). In behavior patterns of types $B$ and $C$, differentiated glandular areas are also found on males' abdomens, but these are less visible and consist of numerous microscopic glandular orifices. This type of microscopic gland is also present in species bearing elaborate cuticular modifications corresponding to type A pattern (Brossut and Roth 1977; Sreng 1984). In all cases however, the sternal and tergal glands producing male pheromones comprise class-3 gland cells (Noirot and Quennedey 1991; Brossut and Sreng 1980).

In addition, these class-3 gland cells are also found in females' glands producing pheromones (e.g. in Blaberidae species - Sreng 2006; or in Ectobiidae species - Liang and Schal 1993). In cockroach species in which females emit the sex attractant (assuming the calling posture), pygidial and tergal glands were found in females of several different groups (e.g. Blaberinae, Blattellinae and Blattinae - Sreng 2006).

Hence, in $O$. deusta, the calling posture in females and the courting behavior in males could indicate the glands' location on the body. Numerous cuticular orifices have been found on the supra-valvular area for females, and on the 8th tergite for males. These cuticular pores, assumed to represent the opening of exocrine glands, are connected to cuticular ducts ("noodle-like structures"). The morphology of these glands is in accordance with that of class-3 exocrine glands (Noirot and Quennedey 1974). In fact, these class-3 glandular units, composed of one secretory cell and one canal cell (Noirot and Quennedey 1974; Sreng and Quennedey 1976), are found in most cockroaches' exocrine glands, with a great similarity in differentiation mechanisms and maturation processes (Plattner et al. 1972; Porcheron 1973; Quennedey and Brossut 1975; Gupta 1979; Brossut and Sreng 1980; Farine et al. 1989; Tokro et al. 1993; Sreng 1979a, 1984, 1985, 1998, 2006). 
The location of the pheromone production is species-specific in male cockroaches, but with some general trends related to the type of mating behavior. In males of the Oxyhaloinae subfamily, the differences in mating behavior patterns also correspond to differences in the number and the location of glandular areas (Sreng 1993). Hence, from type A pattern (Nauphoetini tribe) to type B pattern (J. madecassa), the abdominal glands show a decrease in the number of concerned tergites and sternites (Sreng 1993). Moreover, in type $\mathrm{C}$ pattern, this decrease is even more marked with glandular areas located on the anterior part only of the most posterior tergites and sternites. This is consistent with the tergal gland of males of $O$. deusta which is located on the anterior part of the 8th tergite only. No glandular area was found elsewhere on males' tergites and sternites, revealing a drastic reduction in the number of segments bearing the glands. This posterior location of males' gland is congruent with the alternative mating pattern of $O$. deusta. The male can directly orient his glandular area toward the female's head and this way he could estimate her excitatory level by placing his head behind the tip of the female's abdomen.

In females of $O$. deusta, the potential site of pheromone production is also a novelty. Class-3 cells were found at the abdomen tip, revealed by sclerified orifices organised in rosettes, between the valvulae and the paraprocts. This is the first time that a glandular area has been observed in this zone for a species of the Oxyhaloinae subfamily. We have chosen the term "supra-valvular gland" to refer to this female sexual gland. However, this posterior location is still congruent with usual sites of pheromone production in female cockroaches. In fact, the occurrence of glandular areas in the posterior region of the abdomen is general and appears to reach stability in Blaberinae, and probably in Zetoborinae, Epilamprinae and Panesthiinae (Sreng 2006).

Thus, the location of potential sexual glands in females of $O$. deusta is both consistent with what is known in other species of cockroaches (posterior location), and unique at the same time (supra-valvular area). This area corresponds to the 9 th sternite and represents the most posterior glandular area ever described in an Oxyhaloinae female. Similarly, the occurrence of glands on the 8th tergite only, in males of $O$. deusta, has never been described in any species of Oxyhaloinae. The arrangement of the sexual glands in both male and female is congruent with the new and unique pattern of mating behavior observed in the O. deusta species, and constitutes the major deviation from usual gland locations in cockroaches. In a general way, these shifts correspond to a marked reduction in the extent of glandular areas, associated with a posterior position on one abdominal segment only. This combination of specific features in $O$. deusta denotes a strong correlation between changes in the reproductive sequences and evolutionary changes in gland location.

\section{Synthesis and Evolutionary Perspectives}

To discuss our results from an evolutionary point of view, O. deusta has to be resituated as belonging to the Oxyhaloini tribe (within the Oxyhaloinae subfamily) (Roth 1971), but also, in a broader perspective, as a species of the monophyletic clade of the Blaberidae (e.g. Inward et al. 2007; Djernæs et al. 2012; Legendre et al. 2017; Wang et al. 2017). O. deusta presents interesting divergences, but also shares a number of similarities with several members of these groups. 


\section{Some Similarities in the Composition of Sexual Volatiles Related to the Blaberidae Family}

All sexual glands in males or females exist in adults only and are differentiated just before emergence, reaching their maturation 3-4 days after the imaginal moult (Sreng 2006). Thus, the differentiation process of these glands is in close relation to reproduction via the production of sexual pheromones (Sreng 1985, 1998; Sreng et al. 1999). The "Seducin" (i.e. male sex pheromone in the Oxyhaloinae subfamily) mainly consists of three compounds: acetoin, 2-methylthiazolidine and 4-ethylguaiacol (Roth and Dateo 1966). Roth and Dateo (1966) noted that extracts from males of Gromphadorhina portentosa [Schaum, 1853] (type $C$ pattern of mating behavior) are highly attractive to females of $N$. cinerea (type A pattern). This inter-attraction between different species denotes that one or more sex pheromone components may be common to these species. Acetoin seems to be the potential common substance (Sreng 1990, 1993). The female sex pheromone components involved in male attraction in $O$. deusta have not been identified yet. In one of our experiments in the dark room illuminated by red photographic light, we mistakenly introduced into the observation aquarium D. punctata males. Surprisingly, the $D$. punctata males became very excited, quickly courted $O$. deusta females, and then raised their wings exposing tergal glands to the virgin females. This inter-specific attraction between species with different mating patterns, stresses the question of a common membership vs. evolutionary convergences, with (1) common chemical compounds between the various Oxyhaloinae species, but also (2) between $O$. deusta and D. punctata which belong to 2 different subfamilies (Oxyhaloinae and Diplopterinae). In the same way that some authors have grouped some Blattinae species in a "Periplanone group" (Gemeno and Schal 2004; Persoons et al. 1990; Takegawa and Takahashi 1989; Ho et al. 1992), we could imagine a kind of "Seducin group" bringing together several subfamilies of the Blaberidae group according to common chemical compounds. Inter-subfamilial relationships within this group are still unresolved (Legendre et al. 2017; Wang et al. 2017) and the comparative study of pheromones could possibly bring important insight into Blaberidae phylogenetics. Concerning the occurrence of potential common chemical compounds between $O$. deusta and D. punctata, the two latter studies offer slightly different perspectives. On one hand, in the topology proposed in the paper of Wang et al. (2017), the hypothesis of a paraphyly (between Diplopterinae and Oxyhaloinae), and thus of a plesiomophism (with a reversion to a plesiomorphic state in Diplopterinae), is just as parsimonious as that of an evolutionary convergence. On the other hand, in the topology proposed by Legendre et al. (2017), the hypothesis of a paraphyly is much more probable, with a basal plesiomorphism. But, if the character (i.e. chemical compounds) is not inherited from a common ancestor to Diplopterinae and Oxyhaloinae, this could also be an evolutionary convergence. However, without some additional data on both ancestors and descendants of the concerned taxa, we cannot pronounce on one hypothesis more than the other.

\section{Some Divergences in Behavioral Patterns and Anatomy Related to the Oxyhaloini Tribe}

Insect genitalia are known as relevant features in distinguishing species, as well as in assessing their phylogenetic/evolutionary relationships (e.g. Klass 1997; Klass and Meier 2006). This distinction operates very well in cockroaches (Roth 1971; Princis 
1961; McKittrick 1964). Princis (1961) and Roth (1971) note that the male subgenital plate is an excellent character for distinguishing species of the Oxyhaloinae subfamily. This plate has a laterally directed curved pointed projection posterior to each stylus (Princis 1961). McKittrick (1964) even suggests that this shape may be the closest to the ancestral type and that all other shapes of subgenital plates in the Blaberidae could be derived from it by differential reduction. On this basis, Roth (1971) shows how this male subgenital plate enables discrimination between the 3 Oxyhaloinae tribes: Oxyhaloini, Nauphoetini and Gromphadorhini. In fact, the internal genitalia of the 8 genera included in his study are basically similar, but the genital hook (R2) offers an interesting distinction.

Moreover, this discrimination of the 3 Oxyhaloinae tribes on the basis of the genital hook (R2) (Roth 1971) corresponds to their discrimination according to mating behavior (pattern type) (Roth 1971; Sreng 1993) and according to the location and extent of glandular areas (Sreng 1984, 1993). In the Nauphoetini tribe, with type A mating pattern, the genital hook differs in closeness of the apex to the opposite base, and in the position and the shape of the flange near the base (Gurney 1965), while in the species $J$. madecassa, also belonging to the Nauphoetini tribe but with type B pattern, the flange of R2 is nearly absent (Roth 1971). Within the Gromphadorhini tribe, with type C mating pattern, Roth (1971) found an unusually short R2. Finally, in the Oxyhaloini tribe, this R2 differs from all other genera of Oxyhaloinae. This is particularly consistent with the mating behavior described in our study which differs from the usual classification in types A, B or C of behavior pattern (Sreng 1993). Indeed, courtship and mating behaviors (which relies on the emission of sexual pheromones by glandular areas) reflect various forms of sexual selection and are known to be evolutionarily correlated with the shape and the complexity of genitalia (Rowe and Arnqvist 2011). In accordance with this unusual R2, $O$. deusta also exhibits a different morphology of the glandular areas compared with the other Oxyhaloinae species, which consist of a reduction in the extent of these areas in both males and females.

\section{Conclusion}

Our results support the existence of a close connection between sources of pheromone and behavioral sequences during mating. Glands producing pheromones and the associated reproductive behaviors are, like the genitalia, relevant clues to understand the evolutionary changes among cockroach species with different life-histories, and different mating systems, even if some misclassifications on the basis of genitalia are today being revised in the light of molecular analyses (e.g. the case of Anaplecta sp. in Djernæs et al. 2015).

In the Oxyhaloinae subfamily, the occurrence of the three behavioral patterns (even more so with $O$. deusta) among closely related species is striking and makes this group a suitable model for understanding evolutionary changes in various characteristics involved in the reproductive sequences. More information is needed concerning the mating type and the sexual abdominal glands (of males and females) within the cockroach species of the Oxyhaloini tribe, as well as on their ecology in natural environment. Very little is known about this tribe within the Oxyhaloinae subfamily. Preliminary results concerning genetic data of $O$. deusta (Gilles and Sreng, unpublished 
data) indicate that this species differs from the other Oxyhaloinae tribes (i.e. Nauphoetini and Gromphadorhini), whereas the latest phylogeny of Legendre et al. (2017) recognizes the monophyly of the Oxyhaloinae subfamily. Hence, the potential similarities in terms of chemical compounds between $O$. deusta and D. punctata confirm it would be of great interest revising the Oxyhaloinae subfamily and the relationships within the Blaberidae family in the light of molecular data coupled with pheromone comparisons. The monophyly of the Blaberidae family is not debated anymore despite the variety of studies that have addressed the issue (e.g. Inward et al. 2007; Ware et al. 2008; Roth et al. 2009; Djernæs et al. 2012; Djernæs et al. 2015; Legendre et al. 2015, 2017; Wang et al. 2017). However, the links between species within this family remain unclear, as well as within the Blaberoidae group (although the monophyletic clade represented by [Blaberidae + Ectobiidae] seems well accepted - Inward et al. 2007; Djernæs et al. 2012; Legendre et al. 2017; Wang et al. 2017). The refinement of the phylogeny of this Oxyhaloini tribe within Oxyhaloinae, and more broadly within Blaberidae, appears as a logical continuation of this work. The confrontation of behavioural, pheromonal and morpho-anatomical data, with genetic data would allow a better understanding of evolutionary forces responsible for these different reproductive patterns, as well as a better definition of phylogenetic relationships between species.

Acknowledgements We thank Alain Tonetto and the Electron Microscopy Service for the microphotographs. We thanks Julien Vergeot for his help with infography and schematic drawings. We are grateful to Michael Paul for improving the English. We also would like to thank the two anonymous reviewers for their helpful corrections and their comments.

\section{References}

Ah-King M, Barron AB, Herberstein ME (2014) Genital evolution: why are females still understudied? PLoS Biol 12(5):e1001851

Alexander RD, Otte D (1967) The evolution of genitalia and mating behavior in crickets (Gryllidae) and other Orthoptera. Miscellaneous Publications Museum of Zoology University of Michigan 13:1-62

Barth RH (1968) The comparative physiology of reproductive processes in cockroaches. Part I. Mating behavior and its endocrine control. Advances in reproductive physiology 3:167-207

Barth RH (1970) The mating behavior of Periplaneta americana (Linnaeus) and Blatta orientalis Linnaeus (Blattaria, Blattinae), with notes on 3 additional species of Periplaneta and interspecific action of female sex pheromones. Zeitschrift fur Tierpsychologie. J Comp Ethol 27:722-748

Beccaloni GW (2014) Cockroach Species File Online. Version 5.0/5.0. World Wide Web electronic publication. http://Blattodea.SpeciesFile.org [Accessed 18 Feb 2015]

Beccaloni GW, Eggleton P (2013) Order Blattodea. In: Zhang ZQ (ed) animal biodiversity: an outline of higher-level classification and survey of taxonomic richness (addenda 2013), pp 46-48. Zootaxa 3703:182

Bell WJ, Roth LM, Nalepa CA (2007) Cockroaches: ecology, behavior, and natural history. Maryland, Johns Hopkins University Press, Baltimore

Blomquist GJ, Jurenka R, Schal C, Tittiger C (2004) Biochemistry and molecular biology of pheromone production. In: Gilbert L, Iatrou K, Gill S (eds) Comprehensive Molecular Insect Science, vol 3. Pergamon Press, Oxford, pp 705-751

Brossut R, Roth LM (1977) Tergal modifications associated with abdominal glandular cells in the Blattaria. J Morphol 151:259-298

Brossut R, Sreng L (1980) Ultrastructure comparée des glandes exocrines abdominales des Blattaria (Dictyoptera). [Comparative ultrastructure of the abdominal exocrine glands of Blattaria (Dictyoptera)]. Int J Insect Morphol Embryol 9:199-213 
Brossut R, Dubois P, Rigaud J, Sreng L (1975) Étude biochimique de la sécrétion des glandes tergales des Blattaria. [Biochemical study of the secretion of tergal glands in Blattaria]. Insect Biochemistry 5:719732

Djernæs M, Klass KD, Picker MD, Damgaard J (2012) Phylogeny of cockroaches (Insecta, Dictyoptera, Blattodea), with placement of aberrant taxa and exploration of out-group sampling. Syst Entomol 37(1): 65-83

Djernæs M, Klass KD, Eggleton P (2015) Identifying possible sister groups of Cryptocercidae+Isoptera: a combined molecular and morphological phylogeny of Dictyoptera. Mol Phylogenet Evol 84:284-303

Eberhard WG (1985) Sexual selection and animal genitalia. Harvard University Press, Cambridge

Eberhard WG (1991) Copulatory courtship and female cryptic choice in insects. Biol Rev 66:1-31

Eberhard WG (2010) Evolution of genitalia: theories, evidence, and new directions. Genetica 138:5-18

Farine JP, Brossut R, Nalepa CA (1989) Morphology of the male and female tergal glands of the woodroach Cryptocercus punctulatus (Insecta, Dictyoptera). Zoomorphology 109:153-164

Gabe M. (1968) Techniques histologiques. [Histological techniques.] Paris, France, Masson \& Cie

Gemeno C, Schal C (2004) Sex pheromones of cockroaches. In: Cardé RT, Millar J (eds) Advances in insect chemical ecology. Cambridge University Press, Cambridge, pp 179-247

Gemeno C, Snook K, Benda N, Schal C (2003) Behavioral and electrophysiological evidence for volatile sex pheromones in Parcoblatta wood cockroaches. J Chem Ecol 29:37-54

Gupta AP (1979) Hemocyte types: their structures, synonymies, interrelationships and taxonomic significance. In: Gupta AP (ed) Insect hemocytes - development, forms, functions and techniques. Cambridge University Press, Cambridge, pp 85-127

Gurney A (1965) Two new cockroach of the genera Pelmatosilpha and Henschoutedenia, with a key to the West Indian species of Pelmatosilpha (Dictyoptera: Blattaria). Proceedings of the Royal Entomological Society London (B) 34:5-11

Hales RA, Breed MD (1983) Female calling and reproductive behavior in the brown banded cockroach, Supella longipalpa (F). Ann Entomol Soc Am 76:239-241

Ho HY, Yang HT, Kou R, Chow YS (1992) Sex pheromone of the brown cockroach, Periplaneta brunnea, Burmeister. I. Isolation. Bulletin of the Institute of Zoology. Academia Sinica 31:225-230

Inward D, Beccaloni G, Eggleton P (2007) Death of an order: a comprehensive molecular phylogenetic study confirms that termites are eusocial cockroaches. Biol Lett 3(3):331-335

Klass KD (1997) The external male genitalia and the phylogeny of Blattaria and Mantodea. Bonner Zoologische Monographien 42:1-341

Klass KD, Meier R (2006) A phylogenetic analysis of Dictyoptera (Insecta) based on morphological characters. Entomologische Abhandlungen 63:3-50

Legendre F, Nel A, Svenson G, Robillard T, Pellens R, Grandcolas P (2015) Phylogeny of Dictyoptera: dating the origin of cockroaches, praying mantises and termites with molecular data and controlled fossil evidence. PLoS One 10(7):e0130127

Legendre F, Grandcolas P, Thouzé F (2017) Molecular phylogeny of Blaberidae (Dictyoptera, Blattodea), with implications for taxonomy and evolutionary scenarios. European Journal of Taxonomy 291:1-13

Liang D, Schal C (1993) Ultrastructure and maturation of a sex pheromone gland in the female German cockroach, Blattella germanica. Tissue Cell 25:763-776

Maynard-Smith J, Harper D (2003) Animal signals. Oxford University Press, Oxford

McKittrick FA (1964) Evolutionary studies of cockroaches. Memoir of the Cornell University - Agricultural Experiment Station 389:1-197

Monceau K, van Baaren J (2012) Female teneral mating in a monandrous species. Ecology and Evolution 2(7):1426-1436

Mondet C, Abed-Vieillard D, Gauthier P, Farine JP (2008) Could male tergal secretions be considered as a nuptial gift in the Madeira cockroach? Anim Behav 75:451-460

Noirot C, Quennedey A (1991) Glands, gland cells, glandular units: some comments on terminology and classification. Ann Soc Entomol Fr (NS) 27:123-128

Noirot C, Quennedey A (1974) Fine structure of insect epidermal glands. Annu Rev Entomol 19:61-80

Nojima S, Sakuma M, Nishida R, Kuwahara Y (1999a) A glandular gift in the German cockroach, Blattella germanica (L.) (Dictyoptera: Blattellidae): the courtship feeding of a female on secretions from male tergal glands. J Insect Behav 12(5):627-640

Nojima S, Nishida R, Sakuma M, Kuwahara Y (1999b) Nuptial feeding stimulants: a male courtship pheromone of the German cockroach, Blattella germanica (L.) (Dictyoptera: Blattellidae). Naturwissenschaften 86:193-196

Persoons CJ, Ritter FJ, Verwiel PEJ, Hauptmann H, Mori K (1990) Nomenclature of American cockroach sex pheromones. Tetrahedron Lett 31:1747-1750 
Picker MD, Weaving A, Griffiths C (2002) Field guide to the insects of South Africa. Struik Publishers, Cape Town

Plattner H, Salpeter M, Carrel JE, Eisner T (1972) Struktur und funktion des drusenepithels der postabdominalen tergite von Blatta orientalis. [structure and function of the glandular epithelium of the postabdominal tergite of Blatta orientalis]. Z Zellforsch Mikrosk Anat 125(1):45-87

Porcheron P (1973) Les glandes tergales des blattes. Organisation generale de la glande tergale de Leucophaea maderae (Dictyoptera, Blaberoidea, Blaberidae, Oxyhaloinae). [Cockroaches' tergal glands. General organisation of the tergal gland of Leucophaea maderae (Dictyoptera, Blaberoidae, Oxyhaloinae)]. Comptes Rendus de l'Académie des Sciences Serie D 277:77-79

Princis K (1961) Zur systematik der Blattarien. [On the systematic of Blattaria.] Eos 36:427-449

Quennedey A, Brossut R (1975) Les glandes mandibulaires de Blaberus craniifer Burm. (Dictyoptera, Blaberidae), developpement, structure et fonctionnement. [Mandibular glands in Blaberus craniifer Burm. (Dictyoptera, Blaberidae): development, structure and function]. Tissue Cell 7:503-517

Roth LM, Barth RH (1967) The Sense Organs Employed By Cockroaches in Mating Behavior. Behaviour 28(1):58-93

Roth LM (1969) The evolution of male tergal glands in the Blattaria. Ann Entomol Soc Am 62:176-208

Roth LM (1970) Evolution and taxonomic significance of reproduction in the Blattaria. Annu Rev Entomol 15:75-96

Roth LM (1971) The male genitalia of Blattaria. VI. Blaberidae: Oxyhaloinae. Psyche 78:84-106

Roth LM, Dateo GP (1966) A sex pheromone produced by males of the cockroach Nauphoeta cinerea. J Insect Physiol 12:255-265

Roth LM, Willis ER (1952) A study of cockroach behavior. Am Midl Nat 47:66-129

Roth LM, Willis ER (1954) The reproduction of cockroaches. Smithsonian miscellaneous. Collections 122:149

Roth LM, Willis ER (1955) Intra-uterine nutrition of the "beetle-roach" Diploptera dytiscoides (Serv.) during embryogenesis, with notes on its biology in the laboratory (Blattaria: Diplopteridae). Psyche 62:55-68

Roth LM, Willis ER (1958) The biology of Panchlora nivea with observations on the eggs of other Blattaria. Trans Am Entomol Soc 83:195-207

Roth S, Fromm B, Gade G, Predel R (2009) A proteomic approach for studying insect phylogeny: CAPA peptides of ancient insect taxa (Dictyoptera, Blattoptera) as a test case. BMC Evol Biol 9(1):50

Rowe L, Arnqvist G (2011) Sexual selection and the evolution of genital shape and complexity in water striders. Evolution 6(1):41-54

Schal C, Bell WJ (1983) Determinant of dominant-subordinate interactions in males of the cockroach Nauphotea cinerea. Biology of Behaviour 8:117-139

Schal C, Bell WJ (1985) Calling behavior in female cockroaches (Dictyoptera: Blattaria). J Kansas Entomol Soc 58:261-268

Snodgrass RE (1935) Principles of insect morphology. McGraw-Hill Book Company, New York

Sreng L (1979a) Ultrastructure et chimie de la sécrétion des glandes tergales du mâle de Blattella germanica L. (Dictyoptera: Blattellidae). [Ultrastructure and chemistry of the tergal glands' secretion in the male Blattella germanica L. (Dictyoptera: Blattellidae).] Int J Insect Morphol Embryol 8:213-227

Sreng L (1979b) Phéromones et comportement sexuel chez Nauphoeta cinerea (Olivier) (Insecte, Dictyoptere). [Pheromones and sexual behavior in Nauphoeta cinerea (Olivier) (Insect, Dictyoptera).] Comptes Rendus de l'Académie des Sciences Paris, Serie D 289:687-690

Sreng L (1984) Morphology of the sternal and tergal glands producing the sexual pheromones and the aphrodisiacs among the cockroaches of the subfamily Oxyhaloinae. J Morphol 182:279-294

Sreng L (1985) Ultrastructure of the glands producing sex pheromones of the male Nauphoeta cinerea (Insecta, Dictyoptera). Zoomorphology 105:133-142

Sreng L (1990) Seducin, male sex pheromone of the cockroach Nauphoeta cinerea: isolation, identification and bioassay. J Chem Ecol 16:2899-2912

Sreng L (1993) Cockroach mating behaviors, sex pheromones, and abdominal glands (Dyctioptera: Blaberidae). J Insect Behav 6:715-735

Sreng L (1998) Apostosis-inducing brain factors in maturation of an insect sex pheromone gland during differentiation. Differentiation 63:53-58

Sreng L (2006) Cockroach tergal glands producing female sex attractant pheromones and male aphrodisiacs in particular in the subfamily Blaberinae (Blaberidae, Blattaria). European Journal of Entomology 103(4): $817-829$

Sreng L, Quennedey A (1976) Role of a temporary ciliary structure in the morphogenesis of insect glands. An electron microscope study of the tergal gland of male Blattella germanica L. (Dictyoptera, Blattellidae). J Ultrastruct Res 56:78-95 
Sreng L, Leoncini I, Clement JL (1999) Sex pheromone regulation in the male Nauphoeta cinerea cockroach: role of the brain extracts, corpora allata $(\mathrm{CA})$ and juvenile hormone (JH). Arch Insect Biochem Physiol 40:165-172

Stay B, Roth LM (1958) The reproductive behavior of Diploptera punctata (Blattaria: Diplopteridae). Proceedings of the 10th international congress of Entomology 1956 2:547-552

Takegawa H, Takahashi S (1989) Sex pheromone of the Japanese cockroach, Periplaneta japonica Karny (Dictyoptera: Blattidae). Appl Entomol Zool 24:434 440

Tokro PG (1984) Les phéromones sexuelles chez Blattella germanica L. (Insecte, Dictyoptère). Sécrétion d'une phéromone volatile par le pygidium de la femelle. [Sex pheromones in Blattella germanica L. (Insect, Dictyoptera). Secretion of a volatile pheromone from the female's pygidium.] Doctoral thesis, University of Dijon, France

Tokro PG, Brossut R, Sreng L (1993) Mise en évidence de la phéromone sexuelle chez les femelles de Blattella germanica L. [Evidence for the sex pheromone in female Blattella germanica L]. Insect Science and its Application 14:115-126

Wang Z, Shi Y, Qiu Z, Che Y, Lo N (2017) Reconstructing the phylogeny of Blattodea: robust support for interfamilial relationships and major clades. Nature. Sci Rep 7:3903

Ware JL, Litman J, Klass KD, Spearman LA (2008) Relationships among the major lineages of Dictyoptera: the effect of outgroup selection on dictyopteran tree topology. Syst Entomol 33(3):429-450

Willis ER (1970) Mating behavior of three cockroaches (Latiblattella) from Honduras. Biotropica 2:120-128 